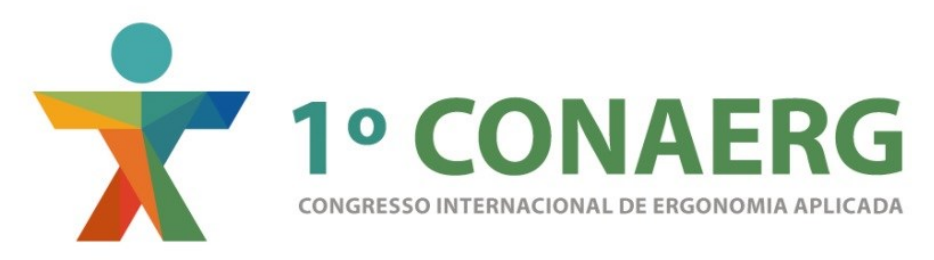

\title{
PREVALÊNCIA DE QUEIXAS MUSCULOESQUELÉTICAS ENTRE OS TÉCNICO-ADMINISTRATIVOS EM EDUCAÇÃO: ESTUDO REALIZADO NA UNIVERSIDADE FEDERAL DE PERNAMBUCO
}

\author{
Ana Cláudia Colaço Lira e Silva (1); \\ Marcelo M. Soares (2); \\ Marcio Alves Marçal (3).
}

(1) Programa de Pós-Graduação em Ergonomia, Universidade Federal de

Pernambuco, mestre em ergonomia,

e-mail: claudiaclira@gmail.com

(2) Programa de Pós-Graduação em Ergonomia, Universidade Federal de

Pernambuco, doutor em ergonomia,

e-mail: soaresmm@gmail.com

(3) Programa de Pós-Graduação em Ergonomia, UFPE - Univ. Fed. dos Vales do Jequitinhonha e Mucuri, doutor em biomecânica ocupacional,

e-mail: marcio@nersat.com.br

\begin{abstract}
RESUMO
Este artigo apresenta um recorte de uma pesquisa realizada a partir da análise ergonômica das atividades laborais de servidores Técnico-Administrativos em Educação (TAE's) que atuam em secretarias de graduação do Centro de Artes e Comunicação da Universidade Federal de Pernambuco, com o objetivo de identificar a prevalência de queixas musculoesqueléticas entre os profissionais. Para tanto, aplicou-se o Método Sistema Humano Tarefa Máquina (SHTM), proposto por Moraes e Mont'Alvão (2012); o Questionário Nórdico e a Termografia digital. Os resultados confirmaram a existência de queixas desta natureza que podem esta relacionadas com fatores físicos envolvidos na realização da tarefa entre os profissionais envolvidos.
\end{abstract}

\begin{abstract}
This article presents part of a survey from the ergonomic analysis of the work activities of Technical Administrative servers in Education (TAE's) working in graduate departments of Arts and Communication Center of the Federal University of Pernambuco, with the objective to identify the prevalence of musculoskeletal complaints among professionals. Therefore, it applied the Human System Method Task Machine (SHTM), proposed by Moraes and
\end{abstract}


Mont'Alvão (2012); the Nordic Questionnaire and digital thermography. The results confirmed the existence of complaints of this nature can this related to physical factors involved in carrying out the task of the professionals involved.

\section{INTRODUÇÃO}

Exibe-se neste artigo, os resultados de uma pesquisa realizada como requisito parcial à obtenção do grau de mestra em Ergonomia, do programa de Pós-Graduação em Ergonomia (PPERGO) da Universidade Federal de Pernambuco (UFPE), na qual procedeu-se um estudo ergonômico nas atividades laborais de servidores TécnicoAdministrativos em Educação (TAE's) que atuam nas secretarias de graduação do Centro de Artes e Comunicação da Universidade Federal de Pernambuco, com o objetivo de identificar a prevalência de queixas musculoesqueléticas entre esta população.

Os profissionais que se utilizam do computador como principal ferramenta de trabalho estão mais suscetíveis a apresentar queixas ou Distúrbios Osteomusculares Relacionados ao Trabalho (DORT's), considerados como o "o principal problema de natureza ergonômica nos tempos atuais no mundo" (COUTO, 2007, p. 78).

Segundo Domingues Júnior (2005) não há um levantamento dos dados no que se refere às queixas musculoesqueléticas na esfera do setor público brasileiro, no qual não se faz uma avaliação das condições de trabalho do servidor, utilizando-se o discurso de que para o servidor público não há prejuízo salarial, pois ele continua recebendo, mesmo nos casos de afastamento do trabalho, podendo estar submetidos a condições de trabalho inadequadas, com níveis de demanda e de controle sobre 0 trabalho que podem levar ao sofrimento e ao adoecimento (RIBEIRO; MANCEBO, 2013; FILHO, 2004).

Neste contexto, promover estudos nesses ambientes de trabalho, podem favorecer ao desenvolvimento das atividades laborais de forma mais saudável e produtiva, uma vez que possíveis falhas no fluxo de trabalho refletem diretamente na saúde e no bemestar dos servidores técnico administrativos em educação (TAE's), bem como na qualidade dos serviços prestados.

\section{PROBLEMÁTICA}

Atualmente, queixas musculoesqueléticas afetam trabalhadores em diversos países do mundo, sendo um diagnóstico comum na Europa. Em 1969, as queixas atingiam 2\% da população mundial; em 1993 atingiam 18\% e recentemente atingem 54\%, (TURCl, 2013).

Por este motivo, representam, além de um desafio de saúde pública relevante, no sentido de melhorar sua prevenção e diagnóstico; um desafio também para os gestores, pois, estas queixas ou lesões são referidas como as principais causas de absentismo e redução da produtividade entre a classe trabalhadora, podendo acometer diferentes partes do corpo, como por exemplo, o ombro e o pescoço, o cotovelo, a mão e o punho o joelho e a coluna vertebral.

As queixas musculoesqueléticas são referidas como as principais causas de absenteísmo e redução da produtividade entre a classe trabalhadora, principalmente a usuária de computador, (OHA et al., 2014).

No Brasil, as queixas musculoesqueléticas despontam como a primeira causa de afastamentos entre trabalhadores que exercem atividades administrativas e 
representam a segunda causa de afastamento entre trabalhadores em geral, (CUNHA, et al., 2009).

Tais morbidades parecem estar associadas com os atuais métodos de organização do trabalho, diante da inserção de novas tecnologias, bem como pela intensificação e fragmentação das atividades em tarefas menores e mais repetitivas. Suas implicações ao trabalhador são ainda mais graves nos países em desenvolvimento, pelas precárias condições de trabalho, baixos salários e acompanhamento médico insuficiente (COMPER; MACEDO; PADULA, 2012).

Vários estudos apontam para a prevalência de queixa musculoesquelética ser mais frequente no sexo feminino do que no sexo masculino (HANVOLD; VEIERSTED; WAERSTED, 2010; PERRY et al., 2009; AUNIVEN et al., 2010; BRIGGS et al., 2009; PAIVA; MARQUES; PAIVA, 2009). Por outro lado, os estudos de Kaspiris et al. (2010) afirmam que há evidência no sentido de ser o sexo masculino o mais afetado com estas queixas.

Segundo Almeida e Martins (2013), esta diferença entre os gêneros pode ser explicada levando-se em consideração alguns fatores: a) a percepção dos sintomas musculoesqueléticos pelos gêneros; b) uma maior flexibilidade muscular no gênero feminino, ou alterações hormonais durante a puberdade; c) a maturação mais precoce do gênero feminino; e d) a imagem de que o gênero masculino é mais forte e por isso não admite este tipo de sintomatologia.

No contexto apresentado, buscou-se amparo teórico nos estudos desenvolvidos em Ergonomia que apresenta como objetivos básicos: "reduzir a fadiga, estresse, erros e acidentes, proporcionando mais saúde, segurança e satisfação para os trabalhadores, durante o seu relacionamento com o processo produtivo" (IIDA, 2005, p. 9).

\section{METODOLOGIA}

As etapas iniciais do método de intervenção ergonomizadora Sistema Humano-tarefamáquina (SHTM), proposto por Moraes e Mont'Alvão (2012) foram utilizadas neste estudo: Apreciação e Diagnose.

Durante a Apreciação Ergonômica, utilizou-se como instrumento para coleta de dados observações assistemáticas, filmagens e registros fotográficos que permitiram reconhecer e categorizar alguns problemas ergonômicos; procedeu-se a investigação e descrição da Unidade Produtiva, em que foi apresentado o sistema alvo em estudo, constituído pelas atividades laborais dos TAE's desenvolvidas nas Secretarias de Graduação; em seguida, realizou-se sua sistematização e a problematização.

$\mathrm{Na}$ Diagnose, visando aprofundar os problemas já identificados e investigar a prevalência de queixas musculoesqueléticas entre a população em estudo, aplicou-se o Questionário Nórdico e a Termografia Infravermelha.

\subsection{O Questionário Nórdico (Nordic Musculoskeletal Questionnaire)}

Corresponde a um formulário de auto-resposta, aplicado com o intuito de identificar a prevalência de sintomas de queixas de dor/desconforto associados ao surgimento de lesões musculoesqueléticas relacionadas com as atividades laborais dos TAE's.

Este questionário é reconhecido mundialmente e por sua simplicidade de aplicação e os bons índices de confiabilidade. Avalia problemas musculoesqueléticos dentro de uma abordagem ergonômica, por esta razão, constitui-se em um importante 
instrumento para identificação dos sintomas osteomusculares no ambiente de trabalho (MESQUITA; RIBEIRO; MOREIRA, 2010; SERRANHEIRA et al., 2003).

Baseado no Mapa de Desconforto Postural de Corlett e Manenica (1980), o Questionário Nórdico é composto por uma figura humana dividida em nove regiões anatômicas, este instrumento abrange também, questões quanto à presença de dores musculoesqueléticas no período de um ano e durante uma semana e se houve incapacidade funcional que levou o trabalhador a procurar por algum profissional da área da saúde nos últimos 12 meses.

\subsection{A Termografia Infravermelha}

Constitui-se em um instrumento recente utilizado em pesquisas científicas. Foi inicialmente utilizada para fins militares e industriais, sendo liberada para uso médico a partir da década de 60, tendo seu primeiro uso entre seres humanos foi como ferramenta de diagnóstico médico (TROTTA; ULBRICHT, 2013).

A câmera termográfica é um instrumento que capta uma representação não visível a olho nu, por meio de imagens de calor (termogramas), a partir de raios infravermelhos capazes de gerar imagens térmicas através de ondas eletromagnéticas, considerando as leis da óptica aplicadas a criação de imagem (ZAPROUDINA et al., 2008).

Desta forma, torna-se assim uma técnica segura, não invasiva e de baixo custo, que permite a gravação rápida de irradiação de energia que é liberada pelo corpo (AMMER; RING, 2014).

Abernathy, Brandt e Robinson (1984) acrescentam que este método mensura as variações de temperatura provenientes de determinada área microvascular do corpo, favorecendo desta forma que o conhecimento sobre a temperatura possa funcionar como um bom indicador de possíveis doenças que podem ser detectadas através de mudanças ocorridas na ordem de graus da pele cutânea ou superficial, (JONES, 1998).

Trotta e Ulbricht (2013, p. 10), enfatizam que "estudos apontam a termografia, com ou sem outros exames de apoio, como importante método complementar na avaliação das doenças musculoesqueléticas em várias áreas anatômicas".

Assim, pelo uso da Termografia Infravermelha, buscou-se perceber possíveis queixas musculoesqueléticas através da temperatura cutânea na captura e análise de imagens térmicas de prováveis áreas com eventuais disfunções dos TAE's.

\section{ANÁLISE E DISCUSSÃO DOS RESULTADOS}

\subsection{Apreciação Ergonômica}

Nesta etapa, procedeu-se a investigação e descrição da unidade produtiva; em seguida, foram realizados a identificação, sistematização e categorização dos problemas ergonômicos.

\subsubsection{Identificação e Descrição da Unidade Produtiva}

A unidade produtiva refere-se a uma Instituição Pública Federal de Ensino Superior denominada Universidade Federal de Pernambuco (UFPE).

(i) Objeto Social: A UFPE presta serviços à sociedade, tendo suas atividades iniciado ainda como Universidade do Recife (UR), em 11 de agosto de 1946, fundada por meio do Decreto-Lei da Presidência da República nº 9.338/46 de 20/06/46. Atualmente a 
UFPE possui doze Centros Acadêmicos, entretanto, a pesquisa foi realizada apenas no Centro de Artes e Comunicação (CAC) no Campus Recife, localizado na Avenida da Arquitetura, s/n, Cidade Universitária, Recife, Pernambuco, CEP 50.740-550. Participaram do estudo 21 (vinte e um) TAE's.

(ii) Público alvo e Tipo de Produção da UFPE: a sociedade, tendo por missão: ensino, pesquisa, extensão e gestão, visando promover um ambiente adequado ao desenvolvimento de pessoas e a construção de conhecimentos e competências que favoreçam para a sustentabilidade da sociedade.

(iii) Atribuições dos TAE's lotados nas Secretarias de Graduação: os TAE's, inseridas no contexto organizacional da Instituição de Ensino Superior Pública Federal (IES) realizam o gerenciamento do(s) curso(s) de graduação, como função básica e fundamental no que diz respeito à vida acadêmica dos alunos, iniciando-se a partir do seu ingresso na Universidade, por aprovação no Sistema de Seleção Unificada (SiSU), gerenciado pelo Ministério da Educação (MEC) ou por transferência interna/externa, de acordo com a legislação em vigor, até a integralização do currículo e a respectiva colação de grau, culminando com sua saída da Universidade para o mercado de trabalho.

Assim, foram identificados: problemas posturais; dimensionais; acionais/ instrumentais e organizacionais/gerenciais.

As figuras que se seguem ilustram alguns problemas ergonômicos identificados.

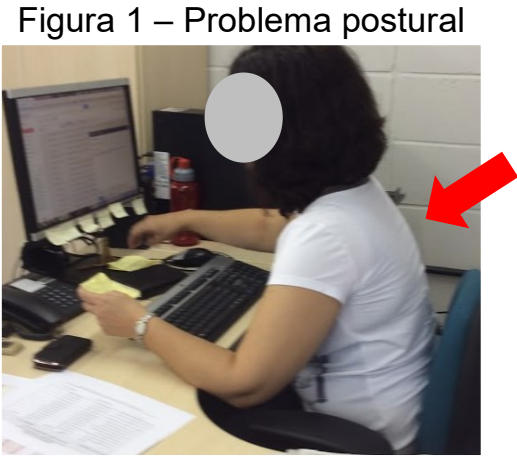

Fonte: autora, 2016.

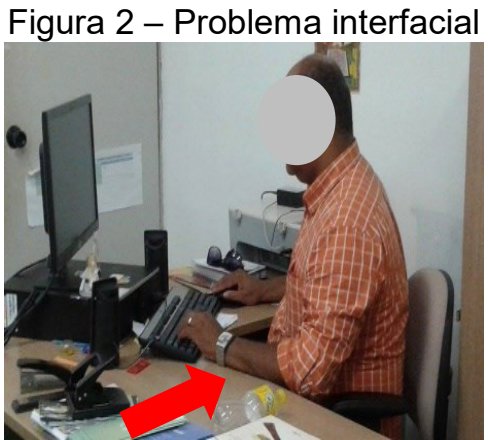

Fonte: autora, 2016.

A Figura 1, evidenciou que a servidora TAE assume uma postura estática com flexão frontal da coluna dorsal, enquanto pratica uma atividade rotineira, realizada diversas vezes durante o horário de expediente. Tal postura poderá acarretar em queixas de dor/desconforto musculoesquelético nas áreas anatômicas envolvidas ou fadiga muscular.

A Figura 2 visualizou a indicação da pressão exercida pela aresta da superfície de trabalho, sobre os tecidos moles do punho e mão, enquanto o servidor TAE digita e acompanha a entrada de dados no teclado e apoia a mão sobre a mesa. Esta posição poderá provocar a compressão dos tecidos do punho e mão, dificultando o fluxo sanguíneo, podendo gerar fadiga e queixas de dor/desconforto musculoesquelético na região tensionada.

Diante da análise e aprofundamento dos problemas identificados, foi possível perceber que os servidores TAE's são expostos há variados níveis de constrangimentos ergonômicos no decorrer da atividade laboral e com isso tornam-se mais vulneráveis da serem acometidos por algum tipo de DORT's. 


\subsection{Caracterização da População}

Foram acrescentadas algumas questões à parte introdutória do questionário nórdico para caracterizar a população do estudo, e a partir de então, verificou-se que na composição da população geral em estudo $(n=21)$, o gênero masculino corresponde a $(n=08)$ e o feminino $(n=13)$, portanto, as mulheres totalizam $62 \%$, enquanto que os homens correspondem a $38 \%$.

Faixa etária: A população foi classificada em duas faixas etárias: acima de 40 anos (com 23,1\% de homens; 76,9\% de mulheres); entre 18 a 39 anos (com 62,5\% de homens e $37,5 \%$ de mulheres), (Gráfico 1 ):

\section{Gráfico 1 - Distribuição da amostra por grupo estratificado - Gênero e Faixa etária.}

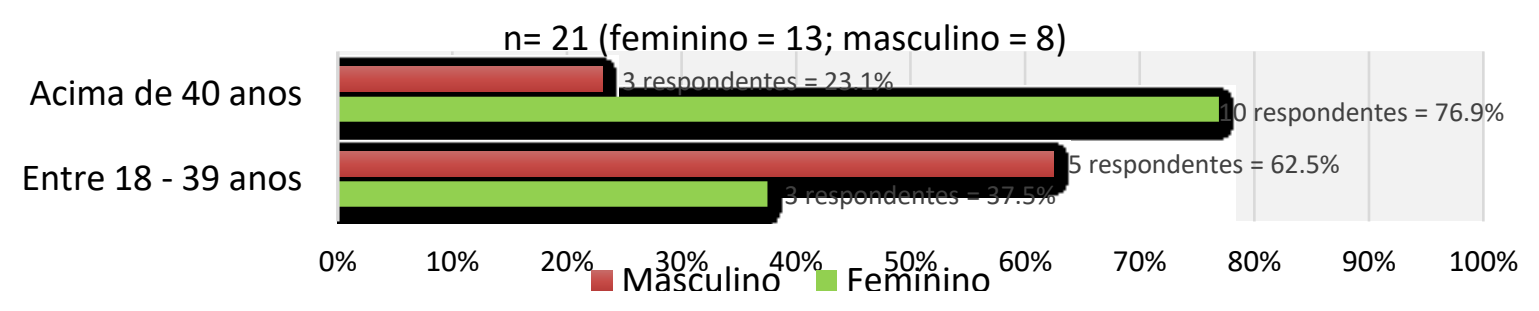

Fonte: autora, 2016

Formação Acadêmica: A população é composta pelo quantitativo de TAE's em estudo com os respectivos níveis de escolaridade assim distribuído: 2 mestres $=9,5 \%$; 08 especialistas $=38,1 \% ; 7$ superior completo $=33,3 \% ; 2$ segundo grau completo $=$ $9,5 \%$ e 2 segundo grau incompleto $=9,5 \%$, totalizando os 21 participantes. Evidenciou-se que a grande maioria dos profissionais envolvidos são graduados e pós-graduados, representando $80,9 \%$ da população (Gráfico 2 ).

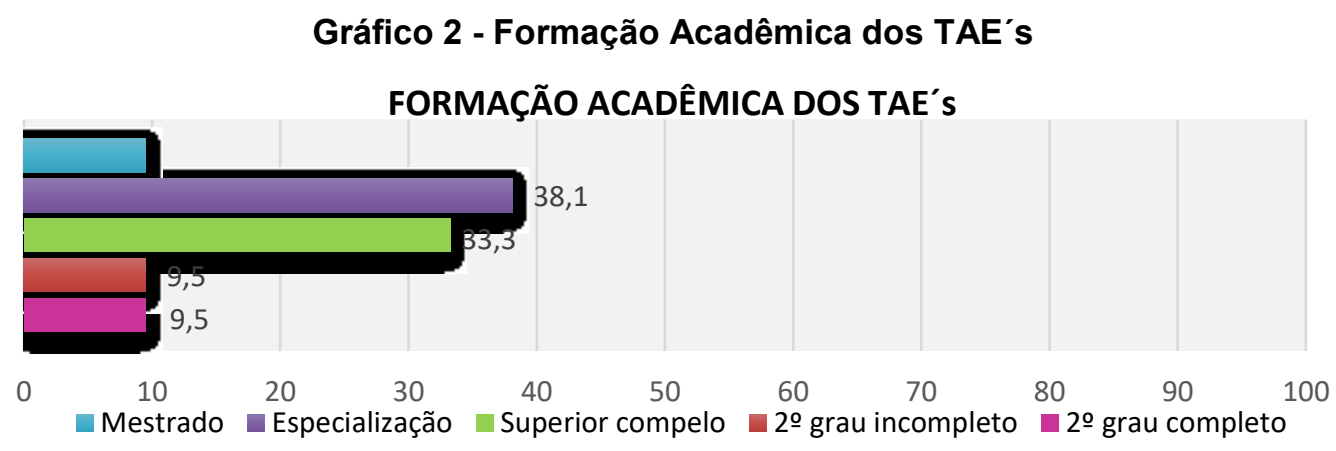

Fonte: autora, 2016

A partir da análise dos dados, evidenciou-se em linhas gerais que a população $(n=21)$ em estudo é maioritariamente feminina. A média de idades entre ambos os sexos é superior a 40 anos.

Em relação a formação acadêmica dos TAE's, os dados apontam para uma formação acadêmica superior ao solicitado inicialmente para ingresso no cargo público que corresponde como exigência ao candidato possuir o segundo grau completo. Isso se deve ao fato de que melhorias salariais estão associadas a capacitação profissional, proposto pelo Ministério da Educação (MEC) definidas na Lei $n^{\circ} 11.091$, de 12 de janeiro de 2005 que propõe as Diretrizes para o desenvolvimento do Servidor Público, bem como o Plano de Carreira dos Cargos Técnico-Administrativos em Educação. 


\section{APLICAÇÃO DO QUESTIONÁRIO NÓRDICO}

\subsection{Prevalência de dor/desconforto nos últimos 12 meses}

Quando analisada a duração dos sintomas no período de 12 meses, evidenciou-se no universo pesquisado $(n=21)$ que todos responderam as 9 questões relacionadas à existência ou não de sintomas para queixas musculoesqueléticas, totalizando 189 respostas, das quais 59 foram positivas ou $31 \%$ e 130 negativas ou $69 \%$.

Verificou-se ainda, dentre os $31 \%$ de casos existentes que a grande maioria das ocorrências de queixas de dor/desconforto no período mencionado foi para o gênero feminino, totalizando 40 casos ou $68 \%$, sendo registradas 19 ocorrências ou $32 \%$ para o gênero masculino (Gráfico 1).

Gráfico 1 - Prevalência de queixas dor/desconforto dos TAE's nos últimos 12 meses

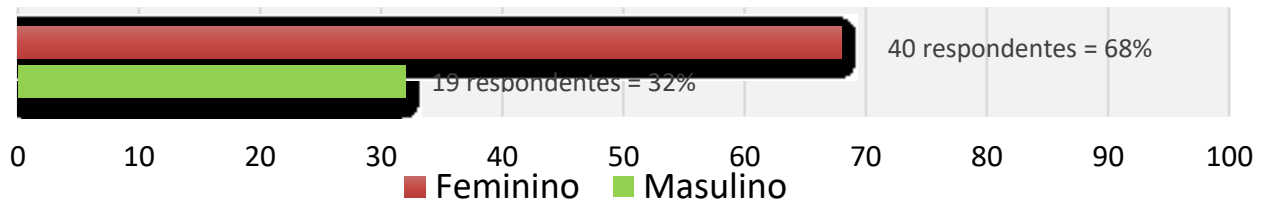

Fonte: autora, 2016

Considerando agora os sintomas por áreas anatômicas com queixas, neste período, evidenciou-se a prevalência de registros em 8(oito) das 9(nove) áreas anatômicas, com exceção do cotovelo, obedecendo a seguinte ordem: coluna lombar com $17 \%$, ombros com $15 \%$, pescoço, punho e mãos, ambos com 13,5\%; coluna dorsal - $12 \%$; e quadril ou coxas com $-11 \%$; tornozelo e pés e joelhos, ambos com $8,5 \%$.

\subsection{Prevalência de Dor/Desconforto nos Últimos 7 Dias}

Dos 21 participantes da pesquisa, houve um total de 50 ocorrências ou $26 \%$ (incluindo registros de queixas em mais de uma área anatômica por respondente, tanto para gênero masculino como para o gênero feminino). Nesse novo período, o universo feminino, permaneceu representando o grupo que afirma mais queixas de dor/desconforto musculoesquelética com 33 ocorrências ou $66 \%$ dos casos. No universo masculino, houve 17 ocorrências ou $34 \%$ dos casos (Gráfico 2).

\section{Gráfico 2 -}

Prevalência de queixa ou desconforto dos TAE's estratificado por SEXO - 7 dias

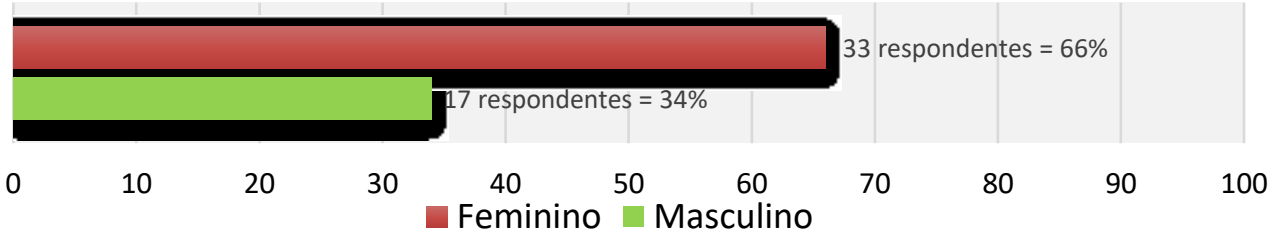

Fonte: autora, 2016 
Considerando agora os sintomas por áreas anatômicas com queixas, neste período, evidenciou-se a prevalência de registros nas 9(nove) áreas anatômicas, obedecendo a seguinte ordem: coluna lombar e ombros, ambos com $18 \%$, pescoço com $16 \%$, punho e mãos com 14\%; coluna dorsal com $11 \%$; joelhos com $9 \%$; tornozelo ou pés com $8 \%$ : quadril ou coxas com $4 \%$ e cotovelos com $2 \%$.

No geral, e comparativamente, a prevalência de queixas musculoesqueléticas nos últimos 12 meses foi maior nas áreas da coluna lombar, em seguida, despontam os ombros, pescoço, punhos e mãos.

\subsection{Afastamento das Atividades Laborais nos Últimos 12 Meses}

Sabe-se que a população deste estudo foi composta por 21 TAE's. Destes, o gênero masculino corresponde a $(n=8)$ representando $38 \%$ e o feminino $(n=13)$ totalizam $62 \%$. No entanto, verificou-se que foram registrados 11 (onze) afastamentos no período de 12 meses por queixas musculoesqueléticas, sendo todos do gênero feminino, ou seja, $100 \%$ dos casos registrados. Portanto, o quantitativo de afastamentos das atividades laborais no período mencionado corresponde a $5,5 \%$ do universo pesquisado.

\subsection{Comentários e Lições Aprendidas}

O questionário nórdico é amplamente referenciado em diversas pesquisas no Brasil e no mundo com grande aplicação em estudos de situações no trabalho real. E a partir de sua aplicação nesta pesquisa, evidenciou-se uma frequência de queixas musculoesqueléticas entre os TAE's ilustradas na Tabela 9, distribuídas por gênero nos respectivos períodos:

Tabela 9 - Resumo das prevalências de queixas (dor ou desconforto) pelo Gênero

\begin{tabular}{l|c|c}
\hline \multicolumn{1}{c|}{ Queixas musculoesqueléticas } & Feminino & Masculino \\
\hline Últimos 12 meses & $68 \%$ & $28 \%$ \\
\hline Últimos 07 dias & $66 \%$ & $34 \%$ \\
\hline Afastamento da atividade laboral últimos 12 meses & $100 \%$ & -- \\
\hline
\end{tabular}

Fonte: autora, 2016

Cabe registrar diante dos dados apresentados acima que embora o gênero feminino corresponda a $62 \%(n=13)$ do universo pesquisado, foi possível afirmar que as queixas musculoesqueléticas prevalecem para este gênero.

Nesse sentido, os dados encontrados corroboram os apresentados nos estudos de Hanvold, Veiersted e Waersted (2010); Skaggs et al. (2006); Perry et al. (2009); Auniven et al. (2010); Briggs et al. (2009); Paiva, Marques e Paiva (2009) em que a prevalência de queixa/dor musculoesquelética é mais frequente no sexo feminino.

No contexto, acredita-se que a prevalência de queixa/dor musculoesquelética no sexo feminino, justifique-se pela forma como são percebidos tais sintomas, pela maior flexibilidade muscular ou alterações hormonais durante a puberdade, bem como de sua maturação mais precoce que caracterizam este gênero, conforme estudos realizados por Almeida e Martins, 2013. 
Quando comparado com a idade dos TAE's, verificou-se a prevalência da faixa etária acima de 40 anos na população em estudo, constituída por $76,9 \%$ de pessoas do gênero feminino.

Sendo assim, através dos relatos dos TAE's coletados a partir do Questionário Nórdico foi possível identificar a existência de queixas musculoesqueléticas, além das áreas anatômicas mais afetadas, as quais convergem de modo geral com as áreas anatômicas mais afetadas que caracterizam os trabalhadores usuários de computadores: a coluna lombar; a coluna cervical e os membros superiores.

\section{APLICAÇÃO DA TERMOGRAFIA INFRAVERMELHA}

Para investigar a prevalência de queixas musculoesqueléticas entre os profissionais envolvidos no estudo, utilizou-se como instrumento da termografia infravermelha. Este instrumento permite mensurar a temperatura através da captura e análise de imagens térmicas cutâneas de prováveis áreas afetadas.

O procedimento de realização das imagens aconteceu em duas etapas: (1) preparação dos participantes e monitoramento da climatização do ambiente e (2) captura de imagens térmicas.

Os voluntários foram escolhidos aleatoriamente, tendo como critério a participação dos mesmos nas etapas anteriores do estudo. Cumpre ressaltar que o dia da coleta das imagens coincidiu com o período de recesso acadêmico da UPFE - CAC, por esta razão, do total de participantes da pesquisa $(n=21)$, apenas sete TAE's estavam presentes neste dia e manifestaram interesse em participar desta etapa do estudo. Destes, cinco são do gênero masculino dois do gênero feminino, com idades variando entre 35 e 52 anos.

\subsection{Descrição das Imagens Utilizando a Termografia}

Existem diversos modelos de câmeras digitais com resoluções diferenciadas utilizadas pelos pesquisadores, entretanto, neste estudo, foi usada a câmera térmica digital Flir E40, com uma resolução real integrada de $160 \times 120$ pixels (19.200 pixels) e possui sensores que permitem medir as temperaturas variando de $-20^{\circ} \mathrm{C} \mathrm{a}+650^{\circ} \mathrm{C}$.

Esta câmera tem sensibilidade para detectar diferenças de temperatura menores que $0,07^{\circ} \mathrm{C}$ e possui exatidão de $\pm 2{ }^{\circ} \mathrm{C}$ da temperatura absoluta, conforme especificações do fabricante, posicionada a 1,0 $\mathrm{m}$ de distância a frente dos voluntários

Cada TAE foi convidado a posicionar-se de pé, próximo a divisória da sala, os homens sem a camisa e as mulheres apenas com o sutiã. Além disto, foi solicitado que os mesmos retirassem os seus objetos de metal localizados no rosto, pescoço, pulso e dedos, tais como: anéis, aliança, relógio, brincos etc. para que não interferissem no registro da temperatura corporal.

Para as mulheres foi solicitado que usassem uma presilha no cabelo para retirá-lo da área da face. A análise estatística dos dados foi realizada com o auxílio do software SSPS19, no qual foram aplicados o teste de Shapiro-Wilk entre as variáveis medidas.

Em seguida, com a câmera termográfica digital Flir E40, foram registradas as imagens focando na região cervical e na região lombar de cada participante. Apresenta-se alguns exemplos: 
Participante 1 - região cervical

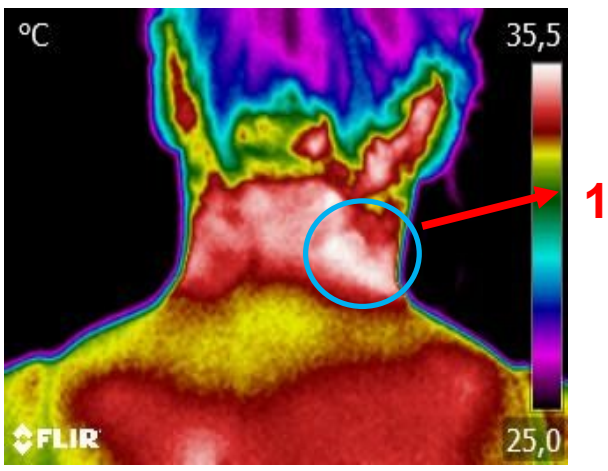

Fonte, autora, 2016.
Participante 4 - Região lombar

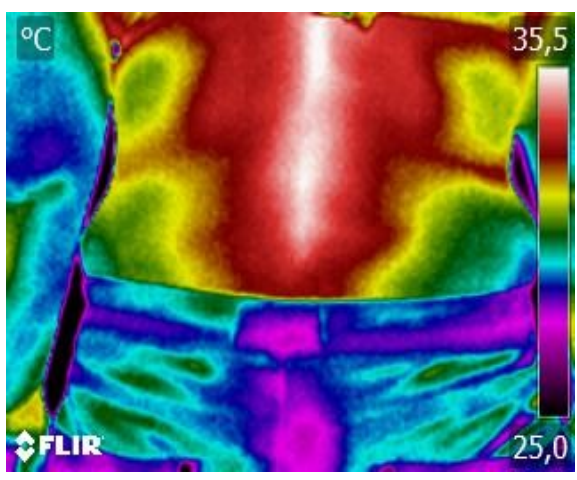

Fonte, autora, 2016.

A imagem do participante 1 evidenciou a região cervical com intensa atividade metabólica, sendo, sugestivo, portanto da existência de queixa musculoesquelética nesta região. Por outro lado, a imagem do participante 4 exibe a região lombar simétrica com aparência normal.

\section{CONCLUSÃO}

Diante do uso das etapas iniciais do Método SHTM foi possível constatar a existência de alguns problemas ergonômicos provenientes da interação dos profissionais com o posto de trabalho durante o desenvolvimento da atividade laboral, entre os quais: problemas posturais interfaciais, posturais dimensionais, acionais operacionais e organizacionais.

A partir do Questionário Nórdico foi possível constatar a existência de queixas musculoesqueléticas, além das áreas anatômicas mais afetadas, as quais convergem de modo geral com as áreas anatômicas mais afetadas que caracterizam os trabalhadores usuários de computadores: a coluna lombar; a coluna cervical e os membros superiores.

Ao analisar as imagens dos sete participantes obtidas pela Termografia infravermelha, evidenciou-se a existência de queixas musculoesqueléticas presentes entre todos, tendo como áreas mais afetadas, a região cervical e os ombros.

Deste modo, a partir da Termografia infravermelha conseguiu-se uma resposta fisiológica para as queixas musculoesqueléticas relatadas pelos profissionais, legitimando assim com os achados apresentados pelo questionário nórdico, de caráter subjetivo, obtido a partir da percepção dos TAE's.

Os resultados da pesquisa enfatizam a necessidade de melhorias nas condições laborais das atividades dos TAE's, devido a várias posturas assumidas que indicam constrangimentos ergonômicos, que podem contribuir para a existência de queixas musculoesqueléticas e afastamentos da atividade laboral.

Por essa razão, apresentam-se algumas recomendações:

Promover o conhecimento dos riscos ergonômicos aos quais estão expostos esses profissionais, apresentando o produto final desta dissertação há administração central da UFPE, para que o material contribua na operacionalização de possíveis medidas preventivas e avaliação dos níveis de risco de desenvolver DORT's entre esta categoria profissional, em um processo no qual as contribuições da Ergonomia favoreçam melhorias das condições de trabalho e consequentemente na qualidade de 
vida dos trabalhadores que atuam nesses postos, e, portanto, reflita em uma melhor prestação de servidos a sociedade.

Promover estudos observacionais para investigação das variáveis para os riscos ergonômicos envolvendo as tarefas realizadas com o computador e as posturas adotadas pelos TAE's;

Considerando que a UFPE é constituída por doze centros acadêmicos e o estudo foi desenvolvido apenas no Centro de Artes e Comunicação, sugere-se que outras pesquisas sejam realizadas nos demais Centros Acadêmicos, para verificação de possíveis diferenças entre os níveis de fatores de risco de prevalência de queixas musculoesqueléticas com os aspectos ocupacionais entre a população envolvida.

\section{REFERÊNCIAS BIBLIOGRÁFICAS}

ALMEIDA, A. J. C.; MARTINS, R. M. L. Perturbações musculoesqueléticas no adolescente. 2013. Dissertação (Mestrado em Enfer. e Reabilitação) - Escola Superior de Saúde de Viseu, IPV. 2013. Disponível em: http://hdl.handle.net/10400.19/2055.

COUTO, H. Ergonomia Aplicada ao Trabalho - Conteúdo Básico - Guia Prático. Belo Horizonte: Ergo, 2007.

KROEMER, K. H. E, GRANDJEAN, Etienne; Manual de Ergonomia - Adaptando o trabalho ao homem. Trad. Lia Buarque de Macedo Guimarães. 5. ed. Porto Alegre: Artes Médicas, 2005.

HISTÓRIA da Universidade Federal de Pernambuco. Disponível em: $<$ https://www.ufpe.br/ufpenova/index.php?option=com_content\&view=article\&id=57\&Itemid=176 >. Acesso em: 20 nov. 2014.

IIDA, Itiro. Ergonomia: Projeto e Produção. São Paulo: Edgard Blucher, 2005.

ABERNATHY, M.; BRANDT, M. M.; ROBINSON, C. Noninvasive testing of the carotid system. Am Fam Phys, North American, v. 29, p. 157-71, 1984.

ALMEIDA, A. J. C.;MARTINS, R. M. L. Perturbações musculoesqueléticas no adolescente. 2013. Dissertação (Mestrado em Enfermagem e Reabilitação) - Escola Sup.de Saúde de Viseu, IPV. 2013. Disponível em: http://hdl.handle.net/10400.19/2055.

ALVES, M. G. M.; CHOR, D.; FAERSTEIN, E.; LOPES, C. S.; WERNECK.G. L. Versão resumida da "job stress scale": adaptação para o português. Revista de Saúde Pública. São Paulo, v. 38, n. 2, p. 164-71,2004.

AMMER,K.;RING,E. F.Repeatability ofthes tandardviewofboth handsdorsal. Results froma trainingcourse onmedical infrared imaging.Thermology International, Nova York. v. 14, n. 3, p. 100-103, 2014.

BRANDT, M. et al. Association between neck/shoulder pain and trapezius muscle tenderness in office workers. Pain Researchandtreatment. New York, 2014.

BRIGGS, A. M.;SMITH, A. J.;STRAKER, L. M.;BRAGGE, P. Thoracic spine pain in general population: prevalence, incidence and associated factors in children, adolescents and adults: a 
systematic review. BMC MusculoskeletalDisorders, London, v.10, n. 77, 2009. Disp. em:http://www.biomedcentral.com/content/pdf/1471-2474-10-77.pdf

COMPER, M. L.; MACEDO; F.; PADULA,R.S. Musculoskeletalsymptoms, postural dissorders and occupational riskfactors: correlationanalyis. Work. USA. v.41(suppl), n. 1, p. 2445-8, 2012.

CORLETT, E. N.; MANENICA, I. The effects and measurement of working postures. Applied Ergonomics. Vol. 2, No. 1, p. 7-16, 1980.

COUTO, H. Ergonomia Aplicada ao Trabalho - Conteúdo Básico - Guia Prático.Belo Horizonte: Ergo, 2007.

CUNHA, J.B.;BLANK, V. L. G.; BOING, A. F. Time trends of leave in Brazilian civil servants (1995 - 2005). Rev. Bras. Epidemiol. , São Paulo, v.12, nº 2, p. 226-236. Jun. 2009.

DUL, Jan; WEERDMEESTER, Bernard. Ergonomia Prática. 2. ed. São Paulo: Edgard Blucher, 2004.

FILHO, J. M. J. Desenho do trabalho e patologia organizacional: um estudo de caso no serviço público. Revista Produção, Santa Catarina, v. 14, n. 3, p. 058-066, 2004.

GRANDJEAN, Etienne; KROEMER, K. H. E. Manual de Ergonomia - Adaptando o trabalho ao homem. Trad. Lia Buarque de Macedo Guimarães. 5.ed. Porto Alegre: Artes Médicas, 2005.

HANVOLD, T.;VEIERSTED, K. B.;WAERSTED, M. A prospective study of neck, shoulder, and upper back pain among technical school students entering working life. J Adolesc Health., Portugal, v. 46,n. 5, p. 488-494, 2010.

IIDA, Itiro. Ergonomia: Projeto e Produção. São Paulo: Edgard Blucher, 2005.

JONES, B. F. A reappraisal of the use of infrared thermal image analysis in medicine. IEEE Trans. Med. Imaging, USAv. 17, p. 1019-1027,1998.

MARQUES et al. Características biomecânicas, ergonômicas e clínicas da postura sentada: uma revisão biomecânica. Fisioterapia e Pesquisa, São Paulo, v.17, n.3, p. 270-6, jul/set. 2010.

MESQUITA, Cristina Carvalho; RIBEIRO, José Carlos; MOREIRA, Pedro. Portuguese version of the standardized nordic musculoskeletal questionnaire: cross cultural and reliability. J Public Health, North American, v. 18, p. 461-466, 2010.

MORAES, Ana Maria de; MONT'ALVÃO, Claudia. Ergonomia: conceitos e aplicações. 4.ed. Ver. Atualizada e ampliada. Teresópolis, RJ: 2AB, 2012.

OHA, K.; ANIMAGI, L.; PAASUKE M.; GOGGON.D.; MERISALU, E. Individual and work-related risk factors for Musculoskeletal pain: cross-sectional study among Estarian Computer users. BMC Musculoskeletal Disorders, London,v. 15, 2014.

PAIVA, F. M. M. C.; MARQUES, A. A. G.; PAIVA, L. A. R. Prevalência as perturbações musculoesqueléticas vertebrais na adolescência. Revista Referência, Teresina, v. 2, n. 11, p. 93-104, 2009. 
PERRY, M.; STRAKER, L.; O'SULLIVAN, P.; SMITH, A.; HANDS, B. Fitness, motor competence, and body composition are weakly associated with adolescent back pain. J Orthop Sports Phys Ther, North American, v. 39, n. 6, p. 439-449, 2009. Disponível em: http://www.jospt.org/doi/pdfplus/10.2519/jospt.2009.3011

RIBEIRO, C. V. S.; MANCEBO, D. O Servidor Público no Mundo do Trabalho do Século XXI. Psicologia: Ciência e Profissão, Brasília,v.33, n.1, p. 192-207, 2013.

SERRANHEIRA, Florentino; PEREIRA, Mário; SANTOS, Carlos Silva; CABRITA, Manuela. Auto-referência de sintomas de lesões musculoesqueléticas ligadas ao trabalho (LMELT) numa grande empresa em Portugal. Rev.Saúde Ocupacional, São Paulo, p.37-47, 2003.

SERRANHEIRA, Florentino; UVA, A.; LOPES, F. Lesões músculo-esqueléticas e trabalho: alguns métodos de avaliação do risco. Sociedade Portuguesa de Medicina do Trabalho.Cadernos Avulsos 5, Portugal,2008.

SKAGGS, D. L.;EARLY, S. D.;D'AMBRA, P.;TOLO, V. T.;KAY, R. M. Back painand backpacks in school childrenll. J Pediatr Orthop, North American, v. 26, n. 3, p. 358-363, 2006.

TRIVIÑOS, Augusto Nibaldo Silva. Introdução à pesquisa em Ciências Sociais - a pesquisa qualitativa em educação. São Paulo: Atlas, 1995.

TROTTA, J.; ULBRICHT, L. Termografia no Diagnóstico Complementar de Doenças musculoesqueléticas. Pan American Journal of Medical Thermology. Curitiba, v. 2,n.1, p. 713, 2013.

TURCI, Aline Mendonça. Adaptação transcultural para o português do Maastrich Upper Extremity Questionare (MUEQ) para trabalhadores de escritório usuários de computador. 2013. Dissertação (Mestrado) - Programa de Pós-graduação Reabilitação e Desempenho Funcional. Faculdade de Ribeirão Preto, USP, 2013.

ZAPROUDINA, N.; VARMAVUO, V.; AIRAKSINEN, O.; NARHI, M. Reproducibility of infrared thermography measurements in healthy individuals, Physiol.Meas. Great Britain, 29 p. 515524, 2008. 